\title{
UMA REFLEXÃo CRÍTICA SOBRE O BUZZ MARKETING E SUAS IMPLICAÇÕES ÉTICAS COMO ESTRATÉGIA DE COMUNICAÇÃO DE MARKETING
}

\author{
JOSMAR ANDRADE \\ ANA CAROLINA TOLEDO \\ MONIQUE TERRA MARINHO
}


UMA REFLEXÃO CRÍTICA SOBRE O BUZZ MARKETING E SUAS IMPLICAÇÕES ÉTICAS COMO ESTRATÉGIA DE COMUNICAÇÃO DE MARKETING

Resumo: No atual cenário de comunicação de marketing, estratégias diferenciadas como o buzz marketing chamam a atenção dado sua capacidade de conquistar a atenção dos consumidores e envolvê-los nos esforços de comunicação. O presente artigo procura oferecer uma reflexão crítica sobre a questão ética neste tipo de abordagem, já que o consumidor nem sempre está consciente de seu caráter persuasivo.

Palavras-chave: Comunicação Integrada de Marketing; Buzz Marketing; Ética

UNA REFLEXIÓN CRITICA SOBRE BUZZ MARKETING Y SUS IMPLICACIONES COMO ESTRATEGIA DE COMUNICACIÓN DE MARKETING

Resumen: En el escenario actual de comunicación de marketing, estrategias diferenciadas como el buzz marketing llaman la atención dado su capacidad de conquistar la atención de los consumidores, involucrándolos en los esfuerzos de comunicación. El siguiente artículo procura ofrecer una reflexión crítica sobre la cuestión ética en este tipo de aproximación, ya que el consumidor, a menudo, no es consciente de su carácter persuasivo.

Palabras clave: Comunicación Integrada de Marketing; Buzz Marketing; Ética

A CRITICAL REFLECTION ABOUT BUZZ MARKETING AND THE IMPLICATIONS ON MARKETING COMMUNICATION STRATEGY

Abstract: In the current marketing communication scenario, differentiated strategies such as buzz marketing have attracted the attention due to its capabilities to grab the consumers attention and involve them in their communications efforts. This paper aims to offer a critical reflection about ethics in word of mouth strategy, since consumers are not always aware that they are experiencing a persuasive situation.

Key words: Marketing Communication; Buzz Marketing; Ethics 


\section{INTRODUÇÃO}

A evolução das tecnologias de telecomunicações, informática e transporte vem transformando aceleradamente $\mathrm{o}$ ambiente de marketing. $\mathrm{O}$ acesso $\mathrm{a}$ dispositivos tecnológicos cada vez mais sofisticados, disseminados em todos os níveis da sociedade, a rapidez de acesso a redes de contatos e a facilidade de produzir e compartilhar conteúdos midiáticos representam condições para a configuração de um novo perfil de consumidor, que interage, pesquisa, discute e que, cada vez mais, ganha consciência do seu poder em um cenário sociocomunicacional ampliado, como consumidores e cidadãos (CANCLINI, 2008).

Nunca, em toda a história, as pessoas tiveram tantas condições de expressar sua opinião e isso faz com que o boca-a-boca ganhe cada vez mais atenção das organizações, seja para formulação de suas estratégias de abordagem e ativação de redes de comunicação a partir do endosso dos próprios consumidores, seja pela necessidade de monitorar o que está sendo dito e comentado (KERPEN, 2011). Para Kotler e Keller, (2006), o boca-a-boca pode ser considerado como a troca de informações positivas ou negativas diretamente entre indivíduos. E mesmo sendo a forma mais antiga de se realizar a comunicação de marketing, já que independe de meio de propagação para que aconteça, a discussão sobre o boca-a-boca foi praticamente negligenciada na teoria e na prática, até as organizações se atentarem para os efeitos multiplicadores da internet (SILVERMAN, 1997).

Com a internet, tornou-se possível a comunicação de maneira mais veloz e com certa facilidade, excluindo-se limitações geográficas. Goldenberg, Libai e Muller (2001) afirmam que

[...] o crescente uso da internet, possibilitando a internautas comunicarem-se de forma mais rápida, com relativa facilidade, estabeleceu a versão contemporânea deste fenômeno, conhecido como internet word-of-mouth - ou word-of-mouse - como um importante canal para a comunicação de marketing (GOLDENBERG; LIBAI; MULLER, 2001, p.212).

Porém não é possível dizer que se trata de um novo fenômeno, mas sim da potencialização do processo tradicional, de se fomentar redes de comentários entre consumidores em interação. Alguns autores salientam que um dos desafios modernos do marketing é entender melhor os mecanismos destes fluxos 
comunicacionais, que não podem ser analisados a partir dos modelos tradicionais utilizados anteriormente (ANDRADE; MAZZON; KATZ, 2006).

O boca-a-boca ganha importância devido à confiabilidade que se tem na fonte que profere a mensagem, aumentando sua persuasão (ENGEL; BLACKWELL; MINIARD,

2000) e também por ser um atenuador do risco percebido, o que, segundo Hawkins, Mothersbaugh e Best (2007), está associado a um desempenho insatisfatório do produto. Como forma de diminuir esse risco, os consumidores aumentam a busca de informações sobre a oferta. Para Procter e Richards (2002), a importância do boca-a-boca se dá porque "os consumidores não têm que assumir riscos de experimentar novos produtos quando pessoas nas quais eles acreditam podem compartilhar esse risco. Muito melhor que endosso de alguém da TV ou então de um vendedor".

Durante muitas décadas, o sistema tradicional de comunicação era unidirecional, mesmo porque a estrutura de mídia e de tecnologias disponíveis só permitia esse tipo de estratégia. Com isso, as organizações acabavam ocupando o papel de emissores da mensagem, gerando esforços comunicacionais para que suas mensagens alcançassem seus receptores e gerassem alguma resposta deles. Esse fluxo tradicional de comunicação não possibilitava a resposta do emissor e portanto não havia a possibilidade de o emissor contradizer a mensagem ou expressar sua opinião, permanecendo-se passivo nos esforços persuasivos da marca. Porém os consumidores passaram a identificar a intenção que o emissor possui em influenciar seu comportamento, estando mais aparelhados para lidar com episódios persuasivos (FRIESTADT; WRIGHT, 1994).

Dessa forma, os processos interativos que se estabeleceram graças ao advento da internet possibilitam que a informação contenha não somente um fluxo de ida, como também um fluxo de volta da informação, permitindo que os usuários participem e modifiquem o conteúdo e a forma da mensagem original (BELCH; BELCH, 2008).

Dentre todas as estratégias de comunicação boca-a-boca que podem ser consideradas pelo profissional de marketing, uma das possíveis formas é o buzz marketing. $\mathrm{O}$ buzz pode ser considerado como "todo o boca-a-boca a respeito de uma marca. É o agregado de toda comunicação pessoa-a-pessoa, a respeito de um particular produto, serviço ou companhia a qualquer ponto do tempo" 
(ROSEN, 2000, p. 7), geralmente baseado em eventos ou esforços especiais desenvolvidos pelos praticantes de marketing para obter efeito de comentários positivos entre usuários e junto à mídia (OETTING, 2006). Segundo a proposição de Chetochine (2006), a essência do buzz marketing envolve técnicas que estimulam consumidores fiéis a marcas, produtos e serviços (evangelistas) a promoverem uma evangelização sistemática do mercado, criando outros evangelistas. Porém outros autores entendem que não é necessário haver relação anterior do consumidor com a marca, mas somente a propensão de que, ao ser exposto a um evento ou estímulo, sejam ativadas sua atenção e sua motivação a comentar e a propagar a informação adiante, preferencialmente com endosso positivo (HENRY, 2003; HUGHES, 2004; THOMAS JR, 2004). Oosterwijk e Loeffen (2005) lembram que buzz refere-se ao som de diversas pessoas falando. Há traduções no Brasil que chamam esse tipo de estratégia de "marketing de buxixo" (como por exemplo McCONNEL; HUBA, 2005).

Por se tratar de uma estratégia nova e com pouca regulamentação a respeito, cada vez mais utilizada por empresas e organizações, é possível considerar uma discussão ética sobre essa prática, já que, em muitos casos, os consumidores estão sendo expostos a ações desse tipo sem ter plena consciência de que isso está ocorrendo.

Essa é a proposição do presente artigo: realizar um ensaio teórico partindo de uma extensa revisão da literatura e propor uma reflexão ética sobre a utilização de buzz marketing como estratégia de comunicação de marketing. Ao final, serão propostas algumas questões de pesquisa que podem ser desenvolvidas, com impacto tanto na dimensão acadêmica quanto na gerencial.

A razão pela escolha do tema é devido à pouca quantidade de referências teóricas, bem como à não identificação de artigos e trabalhos que reflitam sobre esta questão pelo ponto de vista ético, o que é relevante já que essa estratégia de comunicação vem ganhando importância no composto comunicacional das organizações praticantes de marketing.

\section{TRANSFORMAÇÃO DO AMBIENTE DE COMUNICAÇÃO DE MARKETING}

\subsection{Declínio da propaganda}

Entre todas as ferramentas disponíveis para o desenvolvimento de estra- 
tégias promocionais de organizações praticantes de marketing, a propaganda tradicionalmente ocupou lugar de destaque (BELCH; BELCH, 2008). A confiança do praticante de marketing na força da propaganda sempre residiu na ampla cobertura dos veículos utilizados para disseminar a mensagem e nos resultados positivos obtidos ao longo do tempo. Por esses motivos, desde o surgimento da mídia de massa e da possibilidade de se anunciar, a propaganda recebeu a maior parte dos recursos alocados à comunicação pelas organizações (FOX, 1997; SIVULKA, 1998).

No princípio da atividade, alguns especialistas acreditavam que, quando submetidos a estímulos de propaganda, os indivíduos acabariam emitindo alguma resposta, existindo baixa probabilidade de resistência, inclusive pela elevada frequência de repetição da mensagem que aumentaria a força dos esforços realizados. Entretanto, estudos mostram que os esforços comunicacionais de massa acabam sendo ponderados por algumas resistências que os indivíduos ativam pela repetição da experiência (WOLF, 2005).

Neste sentido, nas últimas décadas as empresas enfrentam mudanças significativas no cenário da comunicação persuasiva, que têm como resultado a queda na eficiência de campanhas e anúncios veiculados em mídia de massa. Há vários fatores capazes de justificar esta tendência: o excesso de mensagens promocionais veiculadas; uma mudança na atitude dos receptores em relação à tentativa de persuasão, desenvolvida a partir de uma expertise no trato com o conteúdo de estímulos promocionais e, simultaneamente, um maior controle legal com diversas restrições e implicações para a veiculação de anúncios (BELCH; BELCH, 2008; FRIESTADT; WRIGHT, 1994; WELLS; MORIARTY; BURNETT, 2006).

O excesso de estímulos cria um cenário de saturação (clutter), com indivíduos expostos aos inúmeros estímulos com intenção persuasiva que permeiam os veículos de comunicação, paisagens e ambientes pelos quais circulam (BEL$\mathrm{CH}$ e BELCH, 2008), o que faz com que as pessoas cada vez mais decidam com maior firmeza o que querem ou não ouvir. E mesmo se a opção for dar ouvidos, muitas vezes os resultados esperados pelo emissor da mensagem não são alcançados, pois a comunicação acaba sendo desprovida de efeitos, ou, na pior das hipóteses, responsável por efeito contrário ao pretendido como, por exemplo, o aumento da resistência ou a contra-argumentação ativa (BAGDIKIAN, 1993; JUGENHEIMER, 1996). 
Outros eventos que também contribuem para o declínio da propaganda são os avanços de tecnologia, que alteraram a forma de se consumir os meios. Equipamentos como os controles remotos, a multiplicação de canais de radiodifusão aberta e da tevê por assinatura, a segmentação de veículos impressos e sites na internet, o advento de gravadores de programação, as tecnologias de download digital de conteúdo, são eventos que ampliaram em muito a possibilidade de escolha do público. Esta condição leva à fragmentação da massa da audiência em nichos cada vez menores. O surgimento de novas mídias acrescido ao alto preço de propagandas tradicionais faz com que anunciantes reduzam o investimento nesse meio tradicional. (BELCH e BELCH, 2008)

Somado a isso, tem-se que o modelo de comunicação interruptiva vem perdendo eficiência, pois cada vez mais o público, colocado na posição de recepção da mensagem, zapeia canais, dedica atenção seletiva a anúncios ou até mesmo uma desatenção inconsciente à mensagem promocional (OOSTERWIJK; LOEFFEN, 2005, p. 1). Todos estes fatores combinados fazem com que a propaganda venha perdendo lenta e gradativamente sua importância como disciplina dominante no planejamento da comunicação integrada de marketing, comparando-se à ascensão das demais disciplinas, tais como as relações públicas, os eventos e patrocínios, a promoção de vendas, o marketing direto e o marketing digital interativo (BELCH; BELCH, 2008).

\subsection{Avanços da internet}

Dentre esses avanços tecnológicos, o que mais alterou as ações de marketing foi o advento da internet. Com sua expansão e popularização, a rede mundial de computadores passou a ser um novo meio de comunicação de marketing, com diversas peculiaridades que a diferenciam dos meios tradicionais. A internet pode ser entendida como um meio de informação e entretenimento. Pelo ponto de vista promocional, ela também serve como distribuidora de mensagens, facilita a interação, com grande importância nas decisões de compra do consumidor, porque pode posicionar mensagens e peças em momentos de busca de informação, de avaliação das ofertas e da própria compra (HAWKINS et.al., 2007). Para o interesse específico do presente trabalho, a internet deve ser encarada como um canal que fomenta e facilita interações e estimula o estabelecimento de redes de comunicação entre consumidores (ANDRADE et. al., 2006). 
Para Drèze e Hussherr (2003), o alcance global e também a possibilidade de se conseguir um marketing pessoa-a-pessoa foram as razões do interesse das empresas por esse meio. Em contrapartida, os consumidores se beneficiam desse meio, pois têm maior controle sobre quando e quais mensagens querem ver, além de fornecer seu próprio conteúdo. (BELCH; BELCH, 2008)

Dessa forma, os gastos com internet crescem vertiginosamente. Nos Estados Unidos, já há sugestões que os investimentos nesse tipo de mídia representaram a maioria dos investimentos em disciplina da Comunicação Integrada de Marketing em 2010 (MEIO \& MENSAGEM, 2011). No Brasil há grande avanço do acesso à internet. A pesquisa TIC Domicílios 2011, do Comitê Gestor da Internet no Brasil, indica que 38\% domicílios já possuam computador com acesso à internet, sendo que $68 \%$ destas conexões são feitas com uso de banda larga fixa (CETIC, 2012). Dadas a extensão territorial do país e as assimetrias sociais, esse número é considerável, mas ainda há um foco muito grande dado à TV, sendo que esse meio corresponde a mais da metade da participação nas verbas dos anunciantes (MURAD, 2011).

Uma das vantagens da internet para os profissionais de Marketing é que as várias conversas e discussões feitas por consumidores e stakeholders podem ser acompanhadas em tempo real e, além disso, ficam todas arquivadas para consultas futuras. É interessante às empresas entender tudo o que está sendo dito sobre a sua marca (CARSON, 2005). Isso se torna extremamente importante em um ambiente no qual as preocupações com mensuração e auditorias de resultados ganham força. (BELCH; BELCH, 2008)

Dessa forma, o boca-a-boca desenvolvido em ambiente digital pode ser usado também como forma de pesquisa, para entender melhor atitudes e predisposições dos consumidores em relação às marcas e produtos (CARSON, 2005).

Porém, não são só profissionais de Marketing que utilizam a internet como fonte de pesquisa. Esse meio é muito utilizado pelos consumidores como forma de buscar informações a respeito de produtos e serviços, influenciando as decisões de compra. Alguns trabalhos mostram que os consumidores já esperam encontrar informações online de empresas, essas fontes inclusive são vistas como valiosas por esses consumidores. A inserção de uma empresa em meio virtual pode impulsionar as vendas off-line e também reduzir o papel dos vendedores. (HAWKINS et al 2007). 


\subsection{Potencialização do boca-a-boca}

O boca-a-boca acontece quando pessoas falam naturalmente a respeito de uma marca, seja positiva ou negativamente. Ele acontece quando as pessoas querem dividir seu entusiasmo ou sua decepção (OOSTERWIJK; LOEFFEN, 2005). É importante sempre considerar o impacto do boca-a-boca negativo, pois segundo Ferguson (2006), as empresas contam com o forte poder de influência de advogados da marca e também com forte poder de influência dos detratores.

Em um ambiente saturado de esforços persuasivos, o boca-a-boca acaba ganhando espaço, já que segundo Belch e Belch (2008) as fontes pessoais são o fator mais influente durante uma decisão de compra, pois acabam sendo uma fonte de informação mais conveniente e confiável.

Para Delre, Jager e Janssen (2006), o processo de difusão de uma mensagem através do boca-a-boca se assemelha a uma epidemia contagiosa, que se espalha pelas pessoas. Nos estudos do boca-a-boca, os adotantes imediatos são os primeiros a serem infectados e vão espalhando sua opiniões para os demais. Porém, não se deve assumir que todos são igualmente suscetíveis ao longo da difusão. Dessa forma, percebe-se que o boca-a-boca não é algo novo e nem dependente da internet, pois ele acontece desde que os seres-humanos começaram a falar. $O$ que acontece é que, com o advento da internet, ele acabou ganhando força, pois as barreiras de tempo e espaço foram quebradas (CARSON, 2005).

Para Ferguson (2008), o boca-a-boca acontece em muitos casos pelo desejo humano de se parecer na moda, daí surge a necessidade de compartilhar notícias e informações com os demais, inclusive sobre produtos. Segundo Ferguson (2008), uma pesquisa realizada pela Sharpe Partners em 2006 mostra que apenas $5 \%$ dos pesquisados se recusariam a passar conteúdo de uma marca aos seus amigos. Independente dos indivíduos terem consciência disso, todos agora são agentes de marketing.

É relevante salientar que mesmo com o crescimento da internet a maioria das conversas ainda ocorrem em âmbito ao vivo. 80\% do boca-a-boca ocorre ao vivo, enquanto só $20 \%$ se referem aos comentários online (AHUJA; MICHELS; WALKER; WEISSBUCH, 2007). Além disso, a consultoria McKinsey estimou que $70 \%$ de toda a economia, independentemente do mercado em que a empresa atua, acaba sendo influenciada pelo boca-a-boca. (ALLARD, 2006)

O boca-a-boca ganha poder principalmente por dois fatores: sua indepen- 
dência da companhia e a possibilidade de se realizar boca-a-boca negativo. Além disso, através do boca-a-boca, o emissor passa de uma postura passiva e receptiva para uma postura de novo emissor (ANDRADE et. al., 2006). Um estudo realizado com companhias áreas norte-americanas mostrou que o boca-a-boca negativo acaba tendo uma influência maior nos resultados financeiros da empresa do que o boca-a-boca positivo. Quando o número de comentários negativos aumenta, aumenta também a queda dos lucros da empresa. (FERGUSON, 2006)

Portanto, os profissionais de Marketing devem considerar em suas estratégias a possibilidade de interação entre consumidores e acima de tudo, devem aceitar o fato de que o consumidor está no comando da comunicação, e não a empresa. Os consumidores não querem mais repassar a mensagem criada pelo Marketing, eles acabam repassando as mensagens que consideram úteis, engraçadas e interessantes (CARSON, 2005).

Acredita-se que em pouco tempo as estratégias de marketing boca-a-boca serão responsáveis pela maior parte dos gastos das empresas em marketing e mídia, sendo responsáveis tanto pela estratégia de planejamento e sua execução, quanto pela avaliação de resultados (CARSON, 2005).

\subsection{Importância dada aos formadores de opinião}

Modelos mais tradicionais da comunicação de massa pressupunham que as funções de comunicadores e de seus destinatários eram desprovidas de relações sociais, culturais e situacionais. Isso não significa dizer que se tratam de indivíduos isolados, desprovidos de grupos sociais, mas sim que esses grupos não interferiam no resultado de um dado esforço de comunicação (KATZ apud WOLF, 2005).

Ao longo do tempo, estudos demostraram que as informações das mídias de massa acabam não influenciando diretamente todo o mercado, mas sim um pequeno grupo de pessoas que através do boca-a-boca acabará influenciando grande parte dos demais. Por essa linha de raciocínio, a opinião de apenas $10 \%$ de indivíduos influencia o comportamento de compra dos outros 90\% (MARSDEN, 2006).

Modelos mais modernos sobre a influência entre pares indicam que as empresas devem saber identificar as fontes capazes de atuar como formadores de opinião. Para Watkins (2005) essas pessoas costumam ser criativas, participati- 
vas, arrojadas e, além disso, amam inovações, geralmente criam sua própria identidade e costumam mostrar com freqüência sua paixão pelos seus interesses. São os formadores de opinião que mais influenciam na geração de boca-a-boca.

Marsden (2006) acredita que esses líderes exerçam influência porque suas opiniões são respeitadas pelos demais. Além disso, os líderes são reconhecidos apenas em sua área de conhecimento dentro de uma categoria específica. Segundo Belch e Belch (2008), para que uma fonte seja persuasiva é importante que ela detenha certa expertise, seja confiável, honesta, ética e acreditável. Todas essas características fazem com que a mensagem passada por um influenciador tenha maior credibilidade e dessa forma se torne uma das estratégias de boca-a-boca mais impactantes, apesar da dificuldade de se mensurar resultados (ALLARD, 2006).

\section{BUZZ MARKETING}

\subsection{Crescimento da importância}

O buzz marketing, dentre as inúmeras definições existentes, pode ser considerado como um processo de comunicação multidimensional, que envia mensagens persuasivas aos consumidores na forma de boca-a-boca, tanto online quanto offline. (AHUJA et.al., 2007).

Pesquisas realizadas pelo GfK NOP com o mercado americano revelaram que em 2005, 92\% dos consumidores consideram o boca-a-boca como a melhor forma de obtenção de ideias e informações sobre novos produtos. Em 1977 essa porcentagem era de apenas 67\%. (CARSON, 2005)

Da mesma forma que cresce a importância do boca-a-boca para os consumidores, crescem também os investimentos em buzz. Segundo a Advertising Age, estimativas mostram que os gastos com essa técnica chegam a US\$150 milhões. (AHUJA et al., 2007)

Esse crescimento de importância vem acompanhado pelo surgimento de associações de estudo sobre o tema, como é o caso da Word-of-Mouth Marketing Association (WOMMA, 2012), que foi fundada no final de 2004 e em 2005 já contava com 150 membros corporativos. A WOMMA criou um Código de Ética e um Quadro de Terminologia acerca dessa nova tendência de marketing (CARSON, 2005). 
Podemos pensar no buzz marketing não como uma ação, mas sim com um resultado decorrente de todas as ações de marketing, inclusive as que não foram controladas pela empresa, já que, segundo Allard (2006, p. 198), trata-se de "usar algum gancho, evento ou promoção para fazer com que consumidores e mídia falem sobre uma campanha".

Independentemente das diversas definições dadas ao buzz marketing, todas convergem em um ponto: o buzz tem um caráter intencional de gerar boca -a-boca. Dessa forma, ele acaba por comercializar e pretender controlar o boca-a-boca, que em sua natureza é espontâneo e aleatório (AHUJA, et al, 2007).

\subsection{Estratégias}

As estratégias de buzz marketing são baseadas no fato de que as atitudes e ações dos indivíduos são influenciadas socialmente pelo comportamento de algumas pessoas. Se boa parte do círculo social de um indivíduo possui um produto, provavelmente esse indivíduo acabará comprando esse produto, mesmo que não necessite dele. (DELRE; JAGER; JANSSEN, 2006).

Dessa forma, há dois principais processos comunicacionais que influenciam os consumidores na compra de um determinado produto: o primeiro é a influência externa que o consumidor recebe através de propagandas e outros esforços realizados por meios de comunicação de massa; o segundo, a influência interna que ele recebe através do boca-a-boca. Essa influência possui certa ligação com o número de adotantes imediatos do produto (BASS, 1969 apud DELRE et al, 2006).

Dentre as estratégias de buzz marketing, uma que chama a atenção é a de "live buzz marketing", ou então, buzz marketing ao vivo. Essa estratégia acaba sendo uma tentativa de recriar ou até comercializar algo que as pessoas fazem desde o começo de sua existência. É um estímulo para o boca-a-boca. Tratamse de estratégias na qual a empresa entra em contato direto com o consumidor ou stakeholders através de pessoas contratadas, podendo ser atores ou até pessoas comuns que aceitem falar sobre a marca ou produto (FOXTON, 2006). A ideia do live buzz marketing é baseada no efeito de eco que uma ação pode gerar. O impulso inicial é dado pela performance realizada pela empresa e o eco é gerado pelos consumidores. O ideal é que o eco seja continuado por todos que ouvirem a mensagem (FOXTON, 2006).

Uma estratégia que pode ser considerada tanto como um tipo de buzz 
marketing ou, pela sua especificidade, como uma modalidade diferente dentre as diversas ações do tipo boca-a-boca (OETTING, 2006) é o marketing viral, que consiste em "criar materiais sobre a marca na internet que façam com que os consumidores os compartilhem com seus amigos" (ALLARD 2006, p. 198). A indicação de sites, o repasse de vídeos, de áudios, de apresentações ou outros tipos de arquivos, que são compartilhados entre agentes em ambiente digital, são exemplos deste tipo de ação que se torna cada vez mais comum na era das redes sociais.

O marketing viral pode ser usado para construir awareness sobre uma marca, que é a consciência pelo público da existência dessa marca e de suas qualidades, e deve se basear na identificação e diálogo com o consumidor, caso contrário se torna apenas uma estratégia de marketing de massa utilizando mídia digital (FERGUSON, 2008). Este autor recomenda que as organizações devem ficar atentas para não focarem toda a estratégia somente em campanhas virais, ela é apenas uma parte de todo o planejamento de comunicação.

Outra estratégia utilizada é incitar o boca-a-boca através de estímulos financeiros, oferecendo remuneração para que a informação desejada seja repassada, como receber descontos em compra de site, caso o consumidor o indique a um amigo. Porém essa estratégia altera a forma tradicional do boca-a -boca, pois os consumidores não se informam sobre a marca por livre e espontânea vontade. Nesse contexto, os indivíduos se tornam quase vendedores do produto/serviço (OETTING, 2006).

Além disso, estão se tornando populares os advergames, que são jogos elaborados pelas empresas e que acabam integrando awareness (consciência sobre a existência da oferta) com entretenimento, sendo uma boa oportunidade para envolver seus consumidores com seu produto, serviço ou mensagem (CURRAN, 2006).

A própria diferenciação de um produto, fazendo com que os consumidores espalhem a novidade, ou a criação de uma história para a marca, criando eventos, ocasiões e relações públicas atuam como estratégia de buzz (OETTING, 2006).

\subsection{Explícito versus Disfarçado}

Existem diferentes técnicas para se realizar buzz marketing, que variam de acordo com o nível de divulgação sobre as reais intenções de persuasão. Uma 
delas é o buzz secreto, no qual o consumidor jamais saberá que aquilo que ele vivenciou era uma performance de alguma empresa. Em seguida, tem-se o live buzz divulgado, no qual durante a performance, os ouvintes não sabem que se trata de um esforço de marketing, porém esse objetivo é revelado no final. Por fim, tem-se a técnica do buzz evidente, no qual o consumidor já percebe desde o início que aquela performance/ação é um esforço de marketing (FOXTON, 2006).

As técnicas apresentadas acima estão baseadas na estratégia de buzz usando-se performance, porém há também estratégias baseadas no contato entre pares de pessoas, nas quais utiliza-se um agente de buzz, que não faz parte da empresa para falar sobre um produto. Geralmente as empresas não pagam seus agentes em dinheiro ou salário, mas sim com amostras grátis ou então pontos para conseguir alguma recompensa. (FOXTON, 2006)

A questão da divulgação é algo que deve ser levado em consideração, pois podem garantir o sucesso ou o fracasso de uma campanha, como destacou Keller (apud OETTING, 2006).

\section{QUESTÕES ÉTICAS}

Devido às transformações ocorridas no cenário de marketing, a ética em comunicação acaba se tornando uma nova ciência na tomada de decisão e atuando como uma nova filosofia da era da informação pois, segundo Antonio Pasquali (apud BECKETT, 2003, p. 42), "[...] vivemos na era da comunicação sem termos moralidade na comunicação".

Para Marling (2002), o estudo da ética envolve uma análise sobre quais as regras, comportamentos e formas de pensamento que fazem com que haja uma melhor (ou pior) existência do ser-humano.

Vargas (2005) propõe que a ética de um indivíduo, grupo, organização ou comunidade, "é a manifestação visível, através de comportamentos, hábitos, práticas e costumes de um conjunto de princípios, normas, pressupostos e valores que regem sua relação com o mundo" (VARGAS, 2005, p. 19-20).

Colocados diante de conflitos e questionamentos sobre qual a melhor forma de agir, indivíduos e organizações são orientados por leis e regulamentos formais, pelas normas morais adquiridas junto ao grupo e que nem sempre estão expressas formalmente, elementos de referência que devem levar em conta para adotar o comportamento efetivo, ético. A área de comunicação de 
marketing, diante dos altos recursos envolvidos, de seu poder de influência sobre meios de comunicação e pela sua natureza persuasiva, é frequentemente colocada em situações de questionamento ético (BELCH; BELCH, 2008).

Kotler e Armstrong (2004) afirmam que, perante a lei, as empresas devem evitar propagandas e declarações falsas e enganosas. Também deve-se evitar propagandas que atraiam os consumidores sob falsos pretextos. Somando-se a isso, o crescimento do uso da internet trouxe novas questões éticas a serem analisadas envolvendo o cyberspace. Por se tratar de uma novidade aos consumidores, muitos deles podem não ter total conhecimento dos serviços online e dessa forma a organização deve pensar por esses consumidores. (STRENSKI, 1995)

Nos E.U.A. há forte pressão legal e, entre os diversos órgãos que regulamentam mensagens de anúncios e comerciais, além de ações de marketing de organizações, há a vigilância da Federal Trade Commission (FTC), responsável por proteger a sociedade contra práticas desleais e enganosas, bem como contra comportamentos anti-competitivos. Nessa condição, se encontra o conceito de “omissão enganosa”, que se refere a não divulgação de uma informação necessária para evitar uma situação capaz de levar o consumidor ao engano (BELCH; BELCH, 2008).

No Brasil, o órgão responsável pelo controle do conteúdo publicitário é o CONAR (Conselho Nacional da Auto-Regulamentação Publicitária), uma organização não governamental, que foi fundada em 1980 e tem como missão "impedir que a publicidade enganosa ou abusiva cause constrangimento ao consumidor ou a empresas" (CONAR, 2011). Esta entidade congrega diferentes associações classistas ligadas à atividade da propaganda, que representam anunciantes, agências de propaganda e veículos. Por não se tratar de um órgão governamental, suas decisões não têm força de lei, mas costumam ser respeitadas e seguidas pelos envolvidos em conflitos. O foco está no conteúdo da mensagem publicitária veiculada e os processos podem ser ativados por denúncias de associados, de consumidores, de ONGs, do governo e de organizações concorrentes. Decisões possíveis de ocorrer envolvem a retirada de campanhas do ar para eventuais correções ou ajustes ou até mesmo a suspensão da campanha.

O CONAR, no entanto, não se restringe a conteúdos de propaganda veiculados em meios de massa. Há, já, no Código Brasileiro de Autorregulamentação 
Publicitária condenação quanto a "[...] proveitos publicitários indevidos e ilegítimos, obtidos por meio de "carona" e/ou "emboscada"... (Artigo 31ํ). Ainda, segundo o órgão, toda campanha publicitária deve ser ostensiva e necessariamente identificada como propaganda (Artigo $9^{\circ}$ ).

Nos E.U.A. a WOMMA criou um código de ética para as práticas do marketing boca a boca que deve ser seguido por seus associados. Os principais valores dessa organização são a confiança, a integridade, o respeito, a privacidade, a honestidade e a responsabilidade. A criação do código de ética reflete o desejo de se "fazer a coisa certa" (WOMMA, 2011). Dessa forma, o código de ética estipula uma conduta padrão que seus associados devem seguir. Inicialmente, todos eles devem exigir que seus influenciadores, engajados em processos persuasivos, divulguem sua identidade, seu relacionamento com a empresa e também a existência de benefício financeiro envolvido no processo. A WOMMA também exige que seja feita uma comunicação honesta a respeito dos produtos ou serviços e os comunicadores devem respeitar os direitos de qualquer foro, online ou offline. Os membros da WOMMA não devem usar crianças menores de 13 anos nas suas campanhas de marketing boca-a-boca e também devem obedecer às regras de mídias específicas em relação às crianças. (WOMMA, 2011)

Kirby (2006) discute interessante questão sobre o trade-off que acontece entre a recomendação ética e o interesse persuasivo do praticante de marketing. O autor diz que uma das maneiras de se evitar resultados negativos de campanhas é realizando todas as atividades de marketing de forma transparente, porém quanto mais transparente uma campanha é, menos efetivo se torna o seu boca-a-boca, já que a credibilidade da fonte é diminuída. Diferente do que o código de ética da WOMMA propõe, ele acredita que a não divulgação de um esforço de marketing em uma campanha pode ser uma parte divertida da interação entre consumidores e empresas. Ele afirma que não existe um padrão ético para essas novas tendências e que nunca haverá um padrão que sirva para todas as práticas.

Uma proposição ética capaz de resumir todos estes pensamentos é que os consumidores têm direito de saber quando a mensagem é comercial e quem está tentando persuadi-lo (BELCH; BELCH, 2008). 


\section{REFLEXÃO CRÍTICA}

O advento de campanhas de buzz marketing mantém-se numa linha tênue entre a eficiência desejável dos investimentos em uma campanha persuasiva e a ética, pois por um lado, os consumidores acreditam mais em uma informação quando esta é proferida por alguém de sua confiança. Porém, se essa pessoa estiver sendo paga ou estimulada disfarçadamente para falar do produto/marca, a confiança diminui, já que é percebido certo esforço persuasivo comunicacional. A estratégia mais lógica para esse caso seria não avisar ao consumidor que a fonte da informação é alguém "contratado" pela empresa. Mas, escondendo essa informação, a empresa retira do consumidor o seu direito de saber que está tentando persuadi-lo.

Do ponto de vista prático, um consumidor descobrir que foi persuadido sem que estivesse ciente da intenção pode gerar um pior resultado para a campanha, pois ele se sente enganado. Um bom exemplo disso foi o caso da campanha de divulgação do celular Sony Ericson T68i, no qual modelos atraentes eram mandados para bares como se fossem turistas e pediam para que pessoas tirassem fotos deles com o novo celular e então lhes apresentavam algumas características do aparelho. Alguns consumidores que descobriram mais tarde que aquela conversa era uma tentativa de persuasão patrocinada por uma marca não se sentiram confortáveis (OETTING, 2006).

Kotler e Armstrong (2004) afirmam que, de acordo com a lei, as empresas devem evitar propagandas e declarações falsas e enganosas e também devem evitar propagandas que atraiam os consumidores sob falsos pretextos. Ser persuadido através de uma conversa estimulada por uma empresa pode ser uma forma de conseguir a atenção de um consumidor, porém essa prática pode ser considerada enganosa, já que não fica explícito que aquela conversa é um esforço promocional de uma organização interessada em influenciar as atitudes de indivíduos.

A falta de foros especializados para discutir problemas éticos neste tipo de comunicação representa problema sério, pois à medida que ações eticamente condenáveis não recebem advertência ou sanções legais, praticantes de marketing sentem-se liberados para investir cada vez mais nesse tipo de estratégia.

A criação da WOMMA nos Estados Unidos pode ser vista como um avanço nesse aspecto. Isso, porém, está longe de ser uma solução definitiva para o 
caso já que, apesar da entidade esperar que seus associados ajam de acordo com seus preceitos, não há formulação de penalidades para aqueles que não o façam. Também é preciso chamar atenção para o fato de quem nem todas as organizações que desenvolvem atividades de boca-a-boca promocional sejam associadas à entidade.

À medida que tais campanhas alcançam resultados esperados em termos de aceitação e de repasse, maiores os investimentos em ações desse tipo; com maiores investimentos maiores as chances de ações criativas, diferenciadas e eficazes. Daí a necessidade de um questionamento sobre a prática, já que também aumenta a probabilidade de que surjam conflitos de disfarce e omissão, além de possíveis contendas entre concorrentes. Desta maneira, parece que será inescapável uma maior necessidade de atenção e vigilância de entidades da sociedade civil que representam os consumidores e do próprio governo.

É possível prever que o Brasil precisará de um órgão semelhante à WOMMA para regularizar, ou ao menos ditar alguns valores a serem utilizados na comunicação do tipo buzz marketing ou marketing viral. Ou que o CONAR abrirá espaço para inclusão, em seu estatuto, de recomendações específicas relativas a este tipo de ação.

A visão de que as campanhas em meio digital devem ser elaboradas sobre os preceitos éticos de campanhas offline, apesar de relevante, desconsidera as diferenças existentes entre o meio digital e o meio offline, o que pode gerar ambiguidades na interpretação das regras estabelecidas. A internet ainda é um fenômeno muito novo, se comparado à propaganda tradicional, muitos consumidores ainda não sabem usar adequadamente essa ferramenta e as empresas devem levar isso em consideração, já que se trata de um ambiente aberto, no qual há espaço para ações anônimas de má fé, ainda que a empresa tenha boas intenções.

\section{QUESTÕES RELEVANTES PARA PESQUISA SOBRE O TEMA}

Por ser um tema pouco estudado até então, há uma extensa gama de possibilidades de pesquisas que sejam relevantes tanto acadêmica quanto gerencialmente.

Pensando pelo ponto de vista gerencial, torna-se importante realizar estudos que meçam a eficiência dessa nova estratégia comunicacional, bem como seus possíveis retornos de investimentos. É preciso avaliar, também, os efeitos de in- 
teração entre ações de buzz e as demais ferramentas. Isto é, quais os efeitos de campanhas que usam, junto a outros métodos, ações do tipo buzz marketing.

Também é possível investigar quais os mecanismos envolvidos com a propensão em comentar e repassar mensagens e quais fatores constituem focos de resistência a ações desse tipo.

Outra área de interesse para pesquisadores interessados no tema envolve a realização de estudos sobre o comportamento de formadores de opinião, seu perfil, suas motivações e interesses. Isso permitiria às empresas criar modelos capazes de melhorar sua busca por influenciadores. Valeria a pena entender, com maior aprofundamento, se há diferenças de comportamento de consumidores em ambientes digitais e em ambientes reais, isto é, se há transformações no modo de agir, de comentar, de difundir ou de criticar esforços de praticantes de marketing por parte de consumidores mais ou menos engajados em ambientes digitais.

Há, também, a possibilidade de estudar-se a percepção ética deste tipo de ação, assumindo-se o ponto de vista dos consumidores. Trabalhos desse tipo podem avaliar o que eles consideram correto, como se sentiriam se fossem abordados por uma ação considerada antiética por eles, e qual o impacto no valor da marca de ações consideradas eticamente discutíveis, tanto em termos do conteúdo veiculado quanto a questão central do disfarce, isto é, se a iniciativa é explícita ou oculta.

Esses estudos seriam capazes de dar um apoio mais sólido para a criação de um código de ética definitivo para campanhas de buzz marketing, bem como para a criação de penalidades àqueles que infringirem esse código.

Sob o ponto de vista acadêmico, é interessante estudar como esses fenômenos podem alterar o comportamento de compra das pessoas, bem como sua relação com organizações praticantes de marketing. É importante também realizar estudos sobre as mudanças comportamentais da sociedade como um todo e sua implicação no ambiente de transações de mercado.

Por fim, faltam estudos sobre o tema com dados referentes ao Brasil, visto que a maioria de pesquisas é realizada tendo como referência o mercado e o público consumidor norte-americano. 


\section{REFERÊNCIAS}

AHUJA, Roshan; MICHELS, Tara; WALKER, Mary; WEISSBUCH, Mike. Teen perceptions of disclosure in buzzmarketing. Journal of Consumer Marketing. Ohio, 2007.

ALLARD, Sthéphane. Myths and promises of buzz marketing. in KIRBY, Justin e MARSDEN, Paul. Connected Marketing, the viral, buzz and word of mouth revolution. Burlington (E.U.A.): Elsevier. Pág 197-201, 2006.

ANDRADE, Josmar; MAZZON, José; KATZ, Sérgio. Boca-a-Boca Eletrônico: Explorando e Integrando Conceitos de Marketing Viral, Buzz Marketing e Word-of-Mouse. Anais do Encontro de Marketing da Anpad (EMA). Rio de Janeiro, 2006

BAGDIKIAN, Ben H. O monopólio da mídia. São Paulo: Scritta, 1993.

BECKETT, Robert. Communication ethics: Principle and practice. Journal of Communication Management. Pg 41, 2003

BELCH, George E.; BELCH, Michael A. Propaganda e Promoção. Uma Perspectiva da Comunicação Integrada de Marketing. McGraw-Hill. 2008.

CANCLINI, Néstor García. Consumidores e cidadãos: conflitos multiculturais da globalização. 7. ed. Rio de Janeiro: Editora UFRJ, 2008

CARSON, Jonathan. Word-of-Mouth Marketing: A New Mandate?. Admap. Oct, n.465, 2005.

CETIC. Centro de estudos sobre as tecnologias da informação e da comunicação. Pesquisa TIC Domicílios 2011: pesquisa sobre o uso das tecnologias de informação e comunicação no Brasil. Disponível em: <www.cetic.br/usuarios/tic/...brasil/apresentacao-tic-domicilios-2011. pdf>. Divulgado em 31 de Maio de 2012. Acessado em 21 de Maio de 2013.

CHETOCHINE, Georges. Buzz Marketing: sua marca na boca do cliente. São Paulo: Financial Times / Prentice Hall, 2006.

CONAR. Conselho Nacional de Autorregulamentação Publicitária. Ética na prática, 2011. Disponível em: <http://www.conar.org.br >. Acessado em 06 de Junho de 2011.

. Código Brasileiro de Autorregulamentação Publicitária, 1978. Disponível em: <http://www.conar.org.br>. Acessado em 21 de Maio de 2013.

CURRAN, Steve. Changing the game. in KIRBY, Justin e MARSDEN, Paul. Connected Marketing, the viral, buzz and word of mouth revolution. Burlington (E.U.A.): Elsevier. Pág 129-147, 2006.

DELRE, Sebastiano; JAGER, Wander; JANSSEN, Marco. Diffusion Dynamics in smallworld networks with heterogeneous consumers. Springer Science+Business Media, LLC, 2006 DRÈZE, Xavier; HUSSHERR, François-Xavier. Internet advertising: Is anybody watching? Journal of Interactive Marketing. 2003.

ENGEL, James F.; BLACKWELL, Roger D.; MINIARD, Paul W. Comportamento do consumidor. 8. ed. Rio de Janeiro: LTC, 2000. 
FERGUSON, Bradley. Black buzz and red ink: the financial impact of negative consumer comments on US airlines. in KIRBY, Justin e MARSDEN, Paul. Connected Marketing, the viral, buzz and word of mouth revolution. Burlington (E.U.A.): Elsevier. Pág 185-196, 2006.

FERGUSON, Rick. Word-of-mouth and viral marketing: taking the temperature of the hottest trends in marketing. Journal of Consumer Marketing. Ohio, 2008.

FOXTON, Justin. Live buzz marketing in KIRBY, Justin e MARSDEN, Paul. Connected Marketing, the viral, buzz and word of mouth revolution. Burlington (E.U.A.): Elsevier. Pág 24-46, 2006.

FOX, Stephen. The Mirror Makers. A history of American advertising \& its creators. Chicago, USA: Illini Books, 1997.

FRIESTAD, Marian e WRIGHT, Peter. The persuasion knowledge model: how people cope with persuasion attempts. Journal of Consumer Research. Jun. V. 21, n. 1, p. 1-27, 1994.

GLADWELL, Malcolm. O ponto da virada. Rio de Janeiro: Sextante, 2009

GOLDENBERG, Jacob; LIBAI, Barak; MULLER, Eitan. Talk of the network: a complex systems look at the underlying process of word-of-mouth. Marketing Letters. v. 12, n. 3, p. 211-223, 2001.

HAWKINS, Del; MOTHERSBAUGH, David; BEST, Roger. Comportamento do consumidor: Construindo a estratégia de marketing. Rio de Janeiro: Elsevier, 2007.

HENRY, Amy. How buzz marketing works for teens. Advertising \& Marketing to Children. v. 4, n. 3, 2003.

HUGHES, Mark. Brands, buzz and business. Admap. Jan., n. 446, 2004.

JUGGENHEIMER, Donald W. Advertising as educator. In: CROSS, Mary (Org.).

Advertising and Culture. Theoretical Perspectives. Westport, USA: Praeger, p. 105-111,1996.

KERPEN, Dave. Likeable Social Media. Nova York (E.U.A.): McGraw Hill, 2011.

KIRBY, Justin. Conclusion: the future of connected marketing. in KIRBY, Justin e MARS-

DEN, Paul. Connected Marketing, the viral, buzz and word of mouth revolution. Burlington (E.U.A.): Elsevier. Pág 267-274, 2006

. Using 'word-of-mouse' in brand marketing. Admap. Oct., n. 454, 2004

KOTLER, Philip e ARMSTRONG, Gary. Princípios de Marketing. $9^{\mathrm{a}}$ ed. Pretince Hall, 2004.

Prentice Hall, 2006.

e KELLER, Kevin L. Administração de Marketing. 12. ed. São Paulo:

MARLING, Randal. Propaganda \& the ethics of persuasion. New York: Broadview Press, 2002.

MARSDEN, Paul. Seeds to spread: how seeding trials ignite epidemics of demand. in KIRBY, Justin e MARSDEN, Paul. Connected Marketing, the viral, buzz and word of mouth revolu- 
tion. Burlington (E.U.A.): Elsevier. Pág. 3-23, 2006.

MCCONNELL, Ben e HUBA, Jackie. Buzzmarketing - Criando clientes evangelistas. São Paulo: M. Books, 2005.

MEIO\&MENSAGEM. Internet: Maior taxa publicitária nos Estados Unidos. Disponível em:<http://www.meioemensagem.com.br/home/midia/noticias/20110614Internet_mantem_a_maior_taxa_publicitaria_nos-EUA >. Acessado em Junho de 2011.

MURAD, Fernando. Mercado cresce $4,77 \%$ no $1^{\circ}$ trimestre. Meio\&Mensagem. Disponível em: <http://www.meioemensagem.com.br/home/midia/noticias/20110523Mercado_crece_477_ no_primeiro_trimestre >. Acessado em Julho de 2011.

OETTING, Martin. How to manage connected marketing. in KIRBY, Justin e MARSDEN, Paul. Connected Marketing, the viral, buzz and word of mouth revolution. Elsevier. pág. 232-266, 2006.

OGILVY, David. A publicidade segundo Ogilvy. São Paulo: Prêmio, 1985.

OOSTERWIJK, Leon e LOEFFEN, Anneke (2005). How to use buzz marketing effectively? A new marketing phenomenon eplained and made practical. Tese de Mestrado. Vasteras (Suécia): Marketing School of Business of the University of Malardalen. Disponível em: <http:// www.buzzmarketinggenerator.point.nl/media/downloads/Full_text_Using_buzz\%2omarketing\%20effectively_Loeff >. Acesso em: 10 Fev. 2006.

PROCTER, Joanne; RICHARDS, Martyn. Word-of-mouth marketing: beyond pester power. Advertising \& Marketing to Children. v. 3, n. 3, 2002

ROSEN, Emanuel. The anatomy of buzz: how to create word-of-mouth marketing. New York (EUA): Doubleday, 2000.

SAVAN, Leslie. The sponsored life: Ads, TV and American culture. Philadelphia (E.U.A.): Temple, 1994.

SILVERMAN, George. How to harness the awesome power of word of mouth. Direct Marketing. Nov., p. 32-37, 1997.

SIVULKA, Juliann. Soap, sex and cigarettes: a cultural history of American advertising. Belmont (E.U.A.): Wadsworth, 1998.

STRENSKI, James. The Ethics of Manipulated Communication. Public Relations Quarterly. pág. 33, 1995.

THOMAS JR., Greg M.. Building the buzz in the hive mind. Journal of Consumer Behaviour. Oct., v. 4, n. 1, p. 64-72, 2004.

VARGAS, Ricardo. Os meios justificam os fins. Gestão baseada em valores: da ética individual à ética empresarial. São Paulo: Pearson Prentice Hall , 2005

WATKINS, Steve (2005). The power of the influence in the youth marketin. Admap. Sep. n.464, 2005. 
WELLS, William, MORIARTY, Sandra e BURNETT, John. Advertising: principles \& practices. 7. ed. New Jersey (E.U.A.): Prentice Hall, 2006

WOLF, Mauro. Teorias das comunicações de massa. Martins Fontes. $2^{\text {a }}$ edição. São Paulo, 2005.

WOMMA. Word of mouth marketing association, 2011. Disponível em: <http://womma.org/ main/ >. Acessado em Maio de 2011.

RECEBIDO EM: 21/05/2013

ACEITO PARA PUBLICAÇÃO: 29/06/2013

\section{Josmar Andrade}

Professor doutor e coordenador do curso de Bacharelado em Marketing da Escola de Artes, Ciências e Humanidades da USP. Graduado em Comunicação Social (Jornalismo) pela ECA/USP e em Administração pela FEA/USP, com Mestrado e Doutorado na FEA/USP. Responsável pelas disciplinas Gestão da Comunicação Integrada e Ética em Marketing na EACH/USP.

\section{Ana Carolina Toledo}

Pós-Graduanda em Gestão de Comunicação e Marketing - ECA/ USP. Bacharel em Marketing pela Escola de Artes, Ciências e Humanidades da USP. Bacharel em Esporte pela Escola de Educação Física e Esporte da USP.

\section{Monique Terra Marinho}

Bacharel em Marketing pela Escola de Artes, Ciências e Humanidades da USP. 
